\title{
Modulation of Respiratory Rhythmogenesis by Chloride- Mediated Conductances during the Perinatal Period
}

\author{
Jun Ren and John J. Greer \\ Department of Physiology, Centre for Neuroscience, University of Alberta, Edmonton, Alberta, Canada T6G 2S2
}

\begin{abstract}
Respiratory rhythmogenesis is modulated by chloride-mediated conductances via $\mathrm{GABA}_{\mathrm{A}}$ and glycine receptors. In this study, we determine the actions of chloride-mediated conductances on respiratory rhythmogenesis in perinatal rats from the time of inception of fetal inspiratory drive through to the newborn period. Data were obtained from perinatal rat models, including (1) recordings of nerve roots and neuronal population discharge from medullary slice and brainstem-spinal cord in vitro preparations, (2) gramicidin perforatedpatch recordings of respiratory neurons in medullary slices, and (3) plethysmographic recordings from unanesthetized pups. The transition from excitatory to inhibitory effects on respiratory rhythmogenesis occurs at approximately embryonic day 19 . By birth, GABA, glycine, and taurine all induce a hyperpolarization of the membrane potential in respiratory medullary neurons and a suppression of respiratory frequency. The age-dependant change in the actions of chloride-mediated conductances is regulated by the development of chloride cotransporters (KCC2 and NKCC1). The function of $\mathrm{KCC} 2$ chloride cotransporter is strongly modulated by $\left[\mathrm{K}^{+}\right]_{0}$, which must be considered when evaluating responses observed using in vitro perinatal preparations.
\end{abstract}

Key words: GABAergic modulation; glycine; medulla; respiration; neonatal; prenatal; taurine

\section{Introduction}

A primary goal of perinatal respiratory research is to identify the neurotransmitter systems responsible for modulating respiratory rhythmogenesis and motoneuron drive. Prenatally, an understanding of the neurochemical control of breathing in utero should provide insights into the mechanisms underlying episodic fetal breathing movements that are important for the maturation of lungs and respiratory neuromuscular systems (Kitterman, 1988; Harding and Hooper, 1996; Greer et al., 1999). Postnatally, the occurrence of central, obstructive, and hypoxia-induced apnea in newborns is related to altered levels of neurochemical drive within medullary respiratory nuclei (Jansen and Chernick, 1991; Bonham, 1995; Ballanyi, 2004). The neurotransmitters GABA and glycine are the principal mediators of fast inhibitory transmission in the mammalian CNS. Synaptic inhibition mediated by GABA and glycine, although not essential for rhythm generation in the neonatal rodent (for review, see Rekling and Feldman, 1998), strongly modulates mammalian respiratory rhythmogenesis and the patterning of motor output (Johnson et al., 1996; Shao and Feldman, 1997; Brockhaus and Ballanyi, 1998; Ritter and Zhang, 2000). However, studies examining the function of GABA and glycine in respiratory control during the neonatal period have yielded equivocal and often contradictory results.

Received Jan. 4, 2006; revised Feb. 15, 2006; accepted Feb. 17, 2006.

This work was supported by grants from the Toronto Hospital for Sick Children Foundation, Alberta Lung Association, and the Canadian Institutes of Health (CIHR). J.J.G. is a Scientist of the Alberta Heritage Foundation for Medical Research (AHFMR), and J.R. is a recipient of CIHR for Sudden Infant Death Syndrome, CIHR for Canadian Lung Association, and AHFMR Fellowships.

Correspondence should be address to Dr. John J. Greer, University of Alberta, Department of Physiology, 513 Heritage Medical Research Centre, Edmonton, Alberta, Canada T6G 2S2. E-mail: john.greer@ualberta.ca.

D01:10.1523/JNEUROSCI.0026-06.2006

Copyright $\odot 2006$ Society for Neuroscience $\quad$ 0270-6474/06/263721-10\$15.00/0
Specifically, whether $\mathrm{GABA}_{\mathrm{A}}$ - and glycine receptor-mediated actions are depolarizing/hyperpolarizing resulting in stimulation/ depression of respiratory frequency in neonates is unclear. In this study, we systematically investigated the effects of chloridemediated conductances via $\mathrm{GABA}_{\mathrm{A}}$ and glycine receptors on the generation of respiratory rhythm in newborn rats and in the fetus from the time of inception of fetal breathing movements. The potential role of taurine, an amino acid that acts via glycine receptors, was also examined. Taurine is in high concentrations within the medulla during the perinatal period (Sturman, 1993), and it has been associated with respiratory depression. Specifically, it reduces respiratory frequency when administered within the cerebral ventricles (Holtman et al., 1983), and taurine levels increase within the ventrolateral medulla during hypoxiainduced depression of newborn breathing (Hoop et al., 1999).

In vitro medullary slice and brainstem-spinal cord preparations isolated from perinatal rats were used to examine the effects of chloride-mediated conductances at the system (respiratory rhythm recorded from motor axons) and cellular (gramicidin perforated-patch recordings of respiratory neurons) levels. Complimentary data were obtained using plethysmographic recordings of unanesthetized rat pups.

\section{Materials and Methods}

Brainstem-spinal cord preparations. Fetal Sprague Dawley rats [embryonic day 17 (E17) to E21] were delivered from timed-pregnant dams anesthetized with halothane $\left(2.5 \%\right.$ delivered in $95 \% \mathrm{O}_{2}$ and $\left.5 \% \mathrm{CO}_{2}\right)$ and maintained at $37^{\circ} \mathrm{C}$ by radiant heat. The timing of pregnancies was determined from the appearance of sperm plugs in the breeding cages. The ages of fetuses were confirmed by comparison of their crown-rump length measurements with those published by Angulo y González (1932). Newborn rats were anesthetized by inhalation of metofane (2-3\%). Embryos and newborns were decerebrated, and the brainstem-spinal 
cord were dissected following procedures similar to those established previously (Smith et al., 1990; Greer et al., 1992). The neuraxis was continuously perfused at $27 \pm 1^{\circ} \mathrm{C}$ (perfusion rate of $5 \mathrm{ml} / \mathrm{min}$; chamber volume of $1.5 \mathrm{ml}$ ) with modified Krebs' solution that contained the following (in mM): $128 \mathrm{NaCl}, 3.0,6.0$ or $9.0 \mathrm{KCl}, 1.5 \mathrm{CaCl}_{2}, 1.0 \mathrm{MgSO}_{4}$, $23.5 \mathrm{NaHCO}_{3}, 0.5 \mathrm{NaH}_{2} \mathrm{PO}_{4}$, and 30 D-glucose (equilibrated with $95 \% \mathrm{O}_{2}-5 \% \mathrm{CO}_{2}$ ).

Medullary slice preparations. Details of the preparation have been described previously (Smith et al., 1991). Briefly, the brainstem-spinal cords isolated from perinatal rats as described above were pinned down, ventral surface upward, on a paraffin-coated block. The block was mounted in the vise of a vibratome bath (VT1000S; Leica, Nussloch, Germany). The brainstem was sectioned serially in the transverse plane starting from the rostral medulla to within $\sim 150 \mu \mathrm{m}$ of the rostral boundary of the pre-Bötzinger complex (preBötC), as judged by the appearance of the inferior olive. A single transverse slice containing the preBötC and more caudal reticular formation regions was then cut (500$750 \mu \mathrm{m}$ thick), transferred to a recording chamber, and pinned down onto a Sylgard elastomer. In some experiments, a HEPES pH-buffered solution was used, in which $24 \mathrm{~mm}$ HEPES replaced $\mathrm{NaHCO}_{3}$ and $\mathrm{NaH}_{2} \mathrm{PO}_{4}$ (gassing with $100 \% \mathrm{O}_{2}, \mathrm{pH}$ adjusted to 7.3 with $\mathrm{NaOH}$ ). Sodium was replaced with choline to examine the dependence of $\left[\mathrm{Cl}^{-}\right]_{\mathrm{i}}$ regulation on $\left[\mathrm{Na}^{+}\right]_{0}$.

Extracellular recording and analysis. Recordings of hypoglossal (XII) nerve roots and cervical (C4) ventral roots were made with suction electrodes. Suction electrodes were also placed into the XII nuclei and preBötC to record extracellular neuronal population discharge from medullary slice preparations. Signals were amplified, rectified, low-pass filtered, and recorded on a computer using an analog-to-digital converter (Digidata 1322A; Molecular Devices, Palo Alto, CA) and data acquisition software (Clampfit; Molecular Devices). Mean values of respiratory frequency relative to control were calculated before and after drug delivery. Values of $\mathrm{EC}_{50}$ and $\mathrm{IC}_{50}$ are defined as the concentration of drug necessary to produce $50 \%$ of the maximum mean measured response. Results were expressed as mean \pm SD. Statistical significance was tested using paired/unpaired difference Student's $t$ test; significance was accepted at $p$ values $<0.05$.

Intracellular recordings from medullary slice preparations. Patch electrodes were fabricated from thin-walled borosilicate glass (1.5 mm external and $1.12 \mathrm{~mm}$ internal diameter; A-M Systems, Everett, WA). The pipette resistances were between 3 and $5 \mathrm{M} \Omega$. All whole-cell and perforated-patch recordings were obtained from the somata of small neurons within the preBötC, localized ventrolaterally to the pars compacta of the ambiguous nucleus. Neurons were approached under visual control using a microscope equipped with an infrared contrast enhancement system (Axioskop; Zeiss, Oberkochen, Germany). To establish whole-cell recording, additional suction was applied to rupture the underlying plasma membrane. Perforated-patch recordings were obtained using identical methods, except mechanical rupture of the plasma membrane was omitted. The progress of perforation was evaluated by monitoring the decrease in the membrane resistance. After the seal formation, series resistance decreased to 30-80 M $\Omega$ within 20-30 min. Gramicidin was dissolved in dimethylsulfoxide (DMSO) $(1 \mathrm{mg} / 100 \mu \mathrm{l}$, stock solution) and was freshly made every $2 \mathrm{~h}$. Stock solution $(2-4 \mu \mathrm{l})$ was then added to $1 \mathrm{ml}$ of intracellular solution just before use. The pipette tips were prefilled with $0.5 \mu \mathrm{l}$ of gramicidin-free pipette solution to avoid contamination of tissue with gramicidin while searching for cells and backfilled with gramicidin-containing $(20-40 \mu \mathrm{g} / \mathrm{ml})$ pipette solution. The standard pipette solution contained the following (in $\mathrm{mM}$ ): 140 K-gluconate, $4 \mathrm{NaCl}, 1 \mathrm{CaCl}_{2}, 10$ EGTA or BAPTA, 10 HEPES, $5 \mathrm{MgATP}$, and $0.3 \mathrm{Na}_{3} \mathrm{GTP}, \mathrm{pH} 7.3$ with $\mathrm{KOH}$.

Whole-cell recordings were initially established in modified Krebs' solution and performed with an NPI Electronics (Tamm, Germany) SEC05LX amplifier. All liquid junction potentials were corrected before seal formation with the compensation circuitry of the patch-clamp amplifier. Neurons with resting membrane potentials $\left(V_{\text {rest }}\right)$ more negative than $-40 \mathrm{mV}$ and overshooting action potentials were analyzed. Data were digitized with an analog-to-digital interface (Digidata 1322A; Mo- lecular Devices) and analyzed with the use of pClamp 9.2 (Molecular Devices).

Pharmacological agents. The following drugs were used: 6-cyano-7nitroquinoxaline-2.3-dione, bicuculline (free base; soluble in DMSO), strychnine (soluble in DMSO), glycine, taurine, muscimol, saclofen, nipecotic acid, tetrodotoxin (TTX), EGTA, BAPTA, bumetanide, and furosemide. Drugs were purchased from Sigma (St. Louis, MO) or Research Biochemicals (Oakville, Ontario, Canada). Stock solutions of drugs were prepared as concentrates. All drugs used in vitro were dissolved in modified Krebs' solution, and the $\mathrm{pH}$ was adjusted to 7.4. Muscimol (soluble in physiological $0.9 \% \mathrm{NaCl}$ saline; $0.5-1 \mathrm{mg} / \mathrm{kg}$ ) and bicuculline (free base, soluble in DMSO; $0.6 \mathrm{mg} / \mathrm{kg}$ ) were administered intraperitoneally in vivo.

In vivo neonatal plethysmoghraphic measurements. Whole-body plethysmographic measurements of frequency and depth of breathing were made from postnatal day 1 (P1) unanesthetized rats of either sex. Pressure changes associated with perinatal rat breathing (produced by the warming and humidifying of inspired air and the subsequent cooling and condensation of expired air) were measured using a $27 \mathrm{ml}$ whole-body plethysmograph chamber, a pressure transducer (model DP103; Validyne, Northridge, CA), and signal conditioner (CD-15; Validyne). The plethysmograph was contained within an infant incubator (model C-86; Isolette, Warminster, PA) to maintain the ambient temperature at the approximate nest temperature of $32^{\circ} \mathrm{C}$.

\section{Results \\ Modulation of respiratory frequency by muscimol, glycine, and taurine \\ Differential responses depending on type of in vitro preparation}

Figure 1A-C shows representative examples of the effects of muscimol $\left(\mathrm{GABA}_{\mathrm{A}}\right.$ receptor agonist), glycine, and taurine on the rhythmic respiratory discharge generated by brainstem-spinal cord (left column) and medullary slice (right column) preparations isolated from P1 rats. A very consistent pattern was observed. Activation of ligand-gated, chloride-mediated conductances resulted in a depression of respiratory frequency in brainstem-spinal cord preparations and an increase of frequency in medullary slice preparations. The population dose-response curves generated from 24 brainstem-spinal cord and 22 medullary slice preparations are presented in Figure $1 D-F$. The muscimol-induced modulation of respiratory frequency generated by brainstem-spinal cord $\left(\mathrm{IC}_{50}\right.$ of $\left.0.31 \mu \mathrm{M}\right)$ and medullary slice $\left(\mathrm{EC}_{50}\right.$ of $\left.0.25 \mu \mathrm{M}\right)$ preparations were antagonized by bicuculline $(3 \mu \mathrm{M})$ but not by strychnine $(1 \mu \mathrm{M})$. The glycine-induced inhibition of brainstem-spinal cord $\left(\mathrm{IC}_{50}\right.$ of $\left.36 \mu \mathrm{M}\right)$ and increase of medullary slice $\left(\mathrm{EC}_{50}\right.$ of $\left.34 \mu \mathrm{M}\right)$ respiratory frequencies were antagonized by strychnine $(1 \mu \mathrm{M})$ but not by bicuculline $(3 \mu \mathrm{M})$. The taurine-induced inhibition of brainstem-spinal cord $\left(\mathrm{IC}_{50}\right.$ of $0.59 \mathrm{~mm})$ and increase of medullary slice $\left(\mathrm{EC}_{50}\right.$ of $\left.0.46 \mathrm{~mm}\right)$ respiratory frequencies were antagonized by strychnine $(1 \mu \mathrm{M})$ but not by bicuculline $(3 \mu \mathrm{M})$. Respiratory frequency was not significantly altered from control values in either preparation by addition of low doses of strychnine or bicuculline on their own. These results demonstrate that the muscimol-induced responses were mediated through $\mathrm{GABA}_{\mathrm{A}}$ receptors and that the taurine/ glycine-induced responses were mediated through glycine receptors.

The next series of experiments examined the effects of increasing the endogenous levels of GABA on respiratory frequency in brainstem-spinal cord and medullary slice preparations. Figure $2 A$ shows representative examples of the effects of bath application of the GABA uptake inhibitor nipecotic acid $(2 \mathrm{~mm})$ to brainstem-spinal cord (left column) and medullary slice (right column) preparations from P1 rats. Population data generated from five brainstem-spinal cord and four medullary slice prepa- 


\section{A}

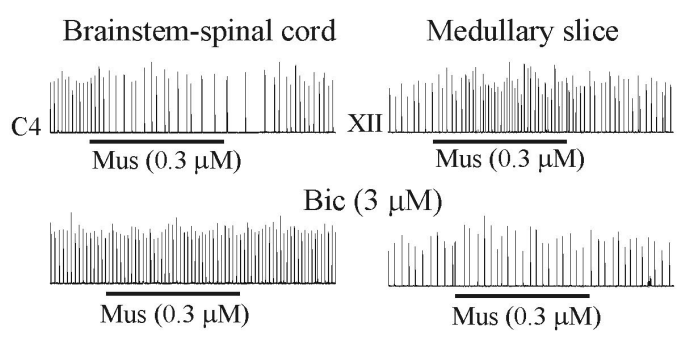

\section{B}
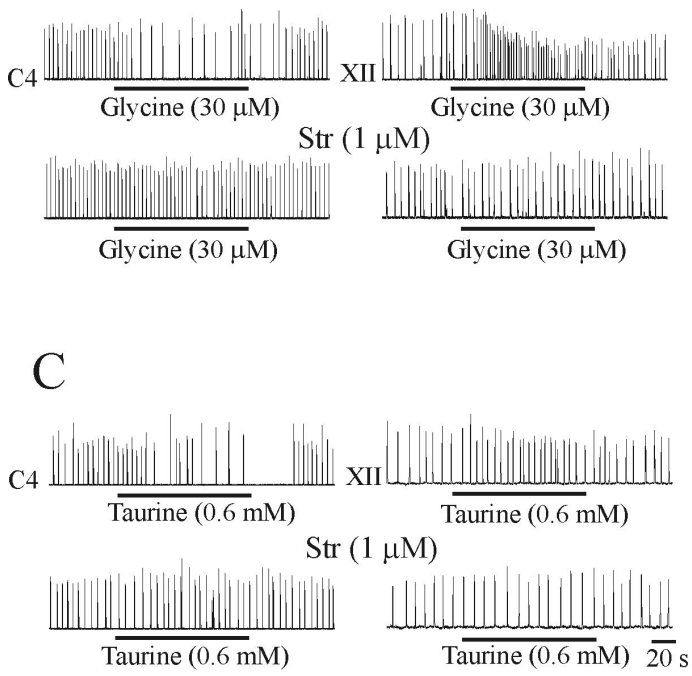

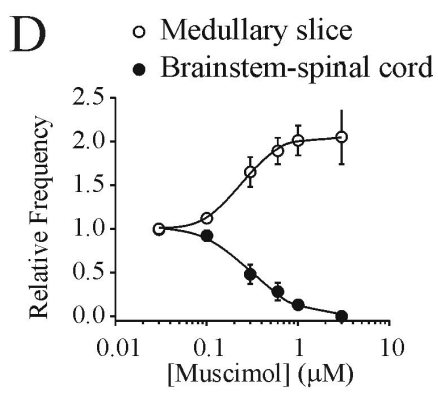

$\mathrm{E}$

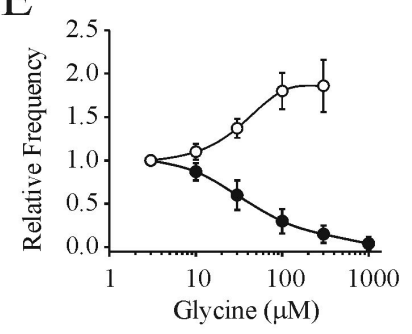

$\mathrm{F}$

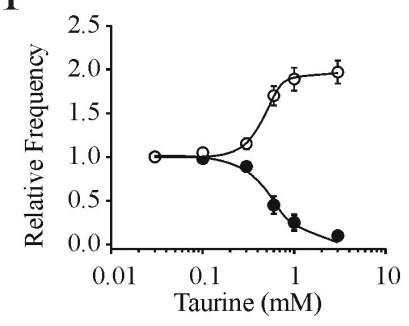

Figure 1. Effects of chloride-mediated conductances on respiratory rhythm generated by brainstem-spinal cord and medullary slice preparations isolated from P1 rats. Rectified and integrated suction electrode recordings of (4 ventral roots (brainstemspinal cord) and XII nerve roots (medullary slice) in response to bath application of the receptor agonists muscimol (Mus; $\boldsymbol{A})$, glycine $(\boldsymbol{B})$, and taurine ( $\boldsymbol{C}$; applied during the time indicated by solid line). The actions of muscimol were antagonized by bicuculline (Bic). The actions of glycine and taurine were antagonized by strychnine (Str). $\boldsymbol{D}-\boldsymbol{F}$, Population dose-response data for each of the agonists added to the media bathing both types of in vitro preparations ( $n=5-6)$. Brainstem-spinal cord and medullary slice preparations were bathed in 3 and $9 \mathrm{~mm}\left[\mathrm{~K}^{+}\right]_{0}$, respectively.

rations are shown in Figure $2 B$. In the brainstem-spinal cord, there was a clear decrease in respiratory frequency after $20 \mathrm{~min}$ of nipecotic acid application. An antagonist to the $\mathrm{GABA}_{\mathrm{B}}$ receptor, saclofen $(400 \mu \mathrm{M})$, was added to the bathing medium to discern the component of the respiratory rhythm suppression resulting from the actions via $\mathrm{GABA}_{\mathrm{B}}$ receptors. These data show that a portion of the respiratory suppression was attributable to $\mathrm{GABA}_{\mathrm{B}}$ receptor-mediated action. Subsequently, bicuculline $(3 \mu \mathrm{M})$ was added to the bathing medium, demonstrating that a significant component of the respiratory frequency depression was attributable to actions via $\mathrm{GABA}_{\mathrm{A}}$ receptors. In medullary slice preparations, there was a slight, but statistically insignificant, increase in respiratory frequency after $20 \mathrm{~min}$ of nipecotic acid application. However, there was a significant increase in respiratory frequency after the administration of saclofen $(400 \mu \mathrm{M})$. This indicates that activation of $\mathrm{GABA}_{\mathrm{A}}$ receptors on their own caused an increase in respiratory frequency in medullary slice preparations. This increase in frequency was antagonized by bicuculline.

$\left[\mathrm{K}^{+}\right]_{o}$ dependency of responses to chloride-mediated conductances As demonstrated above, activation of ligand-gated, chloridemediated conductances consistently resulted in a decrease and increase of respiratory frequency in brainstem-spinal cord and medullary slice preparations, respectively. We investigated two possible mechanisms for this seemingly paradoxical finding. First, we tested the hypothesis that the differential responses were attributable to the indirect actions of other neuromodulators that were present to varying degrees in the two types of in vitro model. The preparation-dependent differential responses persisted in the presence of antagonists to $\mu$-opioid (naloxone, $10 \mu \mathrm{M} ; n=$ 5), NMDA (MK-801 [(+)-5-methyl10,11-dihydro-5H-dibenzo [a,d] cyclohepten-5,10-imine maleate], $30 \mu \mathrm{M} ; n=$ 4), $\alpha 1$ (prazosin, $10 \mu \mathrm{M} ; n=4$ ), $\alpha 2$ (idazoxan, $10 \mu \mathrm{M} ; n=3$ ), nicotinic (Dtubocurarine, $5 \mu \mathrm{M} ; n=3$ ), or muscarinic (atropine, $1 \mu \mathrm{M} ; n=3$ ) receptors, suggesting that indirect modulatory actions were not responsible. Second, we examined whether the markedly different $\left[\mathrm{K}^{+}\right]_{\mathrm{o}}$ in the solutions bathing the brainstem-spinal cord and medullary slice preparations could account for the differential responses. Brainstem-spinal cord preparations produce a robust respiratory rhythm when bathed in physiological levels of 3 $\mathrm{mM}\left[\mathrm{K}^{+}\right]_{\mathrm{o}}$. In contrast, medullary slice preparations are typically bathed in $9 \mathrm{~mm}$ $\left[\mathrm{K}^{+}\right]_{\mathrm{o}}$ to promote the production of robust respiratory discharge for extended periods (i.e., hours). Thus, we performed experiments on both types of preparations isolated from $\mathrm{P} 2$ rats with varying $\left[\mathrm{K}^{+}\right]_{\mathrm{o}}$. It should be noted that spontaneous rhythmic activity persisted for up to $2 \mathrm{~h}$ in some P2 medullary slice preparations cut to a thickness of $750 \mu \mathrm{m}$, which allowed for testing of bath application of muscimol. Figure 3, $A$ and $B$, illustrates representative examples of the effects of muscimol on respiratory frequency in P2 brainstem-spinal cord and medullary slice preparations perfused with medium containing 3, 6 , or $9 \mathrm{mM}\left[\mathrm{K}^{+}\right]_{\mathrm{o}}$. Population data generated from brainstemspinal cord and medullary slice preparations $(n=5$ each) are presented in Figure 3C. Muscimol caused a suppression, no effect, or an increase in respiratory frequency when brainstemspinal cord or medullary slice preparations were perfused with 3, 6 , or $9 \mathrm{mM}\left[\mathrm{K}^{+}\right]_{0}$, respectively. These results demonstrate that muscimol-induced effects are dependent on the $\left[\mathrm{K}^{+}\right]_{\mathrm{o}}$ of the bathing media rather than the type of in vitro preparation per se.

In vivo plethysmoghraphic measurements from neonatal rats We complimented the in vitro experiments with whole-body plethysmographic measurements of frequency and depth of breathing of $\mathrm{P} 1$ rats $(n=5)$ before and after intraperitoneal injection of the $\mathrm{GABA}_{\mathrm{A}}$ receptor agonist muscimol (0.5-1 mg/ $\mathrm{kg}$ ). There was a marked suppression of respiratory frequency similar to that observed with in vitro preparations bathed in $3 \mathrm{~mm}$ $\left[\mathrm{K}^{+}\right]_{\mathrm{O}}$. The muscimol-induced suppression of respiratory frequency was antagonized by a dose of bicuculline $(0.6 \mathrm{mg} / \mathrm{kg})$ that had no significant effects on baseline breathing on its own. 


\section{Developmental changes in the actions} of chloride-mediated conductances

We next examined the age-dependent changes of the actions of chloridemediated conductances during the perinatal period. The inception of respiratory rhythm occurs at approximately E17 in rats (Greer et al., 1992; DiPasquale et al., 1996; Kobayashi et al., 2001; Pagliardini et al., 2003), and thus that was the earliest age examined. Figure $4 A$ shows representative traces of respiratory neuronal discharge recorded from E17, E18, and E20 brainstem-spinal cord preparations in response to bath application of muscimol $(0.3 \mu \mathrm{M})$. Respiratory frequency was increased at E17, not significantly changed at E18, and decreased at E20 by muscimol. Population data generated from 61 brainstem-spinal cord and 65 medullary slice preparations are presented in Figure $4 B$. In medullary slice preparations perfused with $9 \mathrm{~mm}$ $\left[\mathrm{K}^{+}\right]_{\mathrm{o}}$, muscimol increased respiratory frequency from E17 to P5. The suppression of respiratory frequency by muscimol was particularly pronounced in E20 and E21 brainstem-spinal cord preparations.

\section{$\left[\mathrm{K}^{+}\right]_{\mathrm{o}}$ and age-dependent effects on the chloride equilibrium potential}

Perforated-patch recordings of respiratory neurons within the region of the preBötC under various $\left[\mathrm{K}^{+}\right]_{\mathrm{o}}$ conditions and at different developmental ages were performed. Note that $\left[\mathrm{Cl}^{-}\right]_{\mathrm{i}}$ is stable with gramicidin perforated recordings (Kyrozis and Reichling, 1995) as opposed to conventional whole-cell recording that leads to a very rapid dialysis of $\left[\mathrm{Cl}^{-}\right]_{\mathrm{i}}$ (Marty and Neher, 1985).

\section{Muscimol application}

Figure $5 \mathrm{~A}$ shows a perforated-patch recording from an inspiratory (I) neuron in a P2 medullary slice preparation bathed in 9 $\mathrm{mm}$ (left panel) or $3 \mathrm{~mm}$ (right panel) $\left[\mathrm{K}^{+}\right]_{\mathrm{o}}$. Muscimol $(0.3 \mu \mathrm{M})$ evoked a depolarizing response from $V_{\text {rest }}$ of $-52 \mathrm{mV}$ with $9 \mathrm{~mm}$ $\left[\mathrm{K}^{+}\right]_{\mathrm{o}}$ and an increase of respiratory frequency. After switching to $3 \mathrm{mM}\left[\mathrm{K}^{+}\right]_{\mathrm{o}}$, the membrane potential $\left(V_{\mathrm{m}}\right)$ hyperpolarized and stabilized at $-61 \mathrm{mV}$ within $5 \mathrm{~min}$. Subsequent application of muscimol $(0.3 \mu \mathrm{M})$ hyperpolarized $V_{\mathrm{m}}$ and decreased respiratory frequency. Figure $5 B$ demonstrates the reversal potential at P1 for the $G_{A B A}$ receptor-activated membrane response $\left(E_{\mathrm{GABA}-\mathrm{A}}\right)$ of an I neuron using perforated-patch recording in the presence of TTX $(0.3 \mu \mathrm{M})$. In $9 \mathrm{~mm}\left[\mathrm{~K}^{+}\right]_{\mathrm{o}}$ (left panel), application of muscimol ( $3 \mu \mathrm{M}, 30 \mathrm{~s})$ evoked a hyperpolarizing response from a holding potential $\left(V_{\mathrm{h}}\right)$ of $-36 \mathrm{mV}$, whereas it depolarized the neuron from $V_{\mathrm{h}}$ of -52 and $-88 \mathrm{mV}$. $V_{\text {rest }}$ of this neuron in $9 \mathrm{~mm}\left[\mathrm{~K}^{+}\right]_{\mathrm{o}}$ was $-52 \mathrm{mV}$. In $3 \mathrm{~mm}\left[\mathrm{~K}^{+}\right]_{\mathrm{o}}$, the application of muscimol $(3 \mathrm{mM})$ evoked a hyperpolarizing response from $V_{\mathrm{h}}$ of -36 and $-52 \mathrm{mV}$, whereas it depolarized the neuron from a $V_{\mathrm{h}}$ of $-88 \mathrm{mV}$. $V_{\text {rest }}$ was $-60 \mathrm{mV}$ when superfused with $3 \mathrm{~mm}$ $\left[\mathrm{K}^{+}\right]_{\mathrm{o}}$. A linear regression line (Fig. $5 \mathrm{C}$ ) was calculated for the amplitudes of muscimol-evoked responses from the neuron shown in $B$ to determine $E_{\mathrm{GABA}-\mathrm{A}}$. Figure $5 D$ shows the population data for $E_{\mathrm{GABA}-\mathrm{A}}$ and $V_{\text {rest }}$ at 3 versus $9 \mathrm{mM}\left[\mathrm{K}^{+}\right]_{\mathrm{o}}$ at different stages of development for 49 I neurons. In summary, a shift in $\left[\mathrm{K}^{+}\right]_{\mathrm{o}}$ from 3 to $9 \mathrm{~mm}$ caused an $8 \mathrm{mV}$ depolarization of $V_{\text {rest }}$, a
$10-20 \%$ increase in membrane input resistance at all ages from E17 to P4, an $11 \mathrm{mV}$ depolarization of $E_{\mathrm{GABA}-\mathrm{A}}$ at E17-E18, and a $17 \mathrm{mV}$ depolarization of $E_{\mathrm{GABA}-\mathrm{A}}$ from E20 to P4.

Figure $6 \mathrm{~A}$ illustrates a gramicidin perforated-patch recording of an I neuron in a P1 medullary slice bathed in solution containing $9 \mathrm{~mm}\left[\mathrm{~K}^{+}\right]_{\mathrm{o}}$ and $0.3 \mu \mathrm{M}$ TTX. There was a dose-dependent depolarization (from $V_{\text {rest }}$ of $-50 \mathrm{mV}$ ) and reduction in input resistance in response to muscimol application. The population dose-response data for five I neurons is shown in Figure $6 B$. Bicuculline $(3 \mu \mathrm{M})$ antagonized the depolarizing actions of lower doses of muscimol. The effects of relatively high doses of musci$\mathrm{mol}(3 \mu \mathrm{M})$, used in past studies, on $V_{\mathrm{m}}$ of an I neuron and XII nerve root respiratory activity at $\mathrm{P} 1$ is shown in current-clamp (Fig. 6C) and voltage-clamp (Fig. 6D) modes. Muscimol application caused a depolarization of $V_{\mathrm{m}}$ and an in inward current. There was an initial increase in the frequency of inspiratory discharge followed by suppression of spiking in the neuron and the amplitude of the XII nerve recording. The combination of sodium channel inactivation and shunting of inward glutamatergic currents that occurs with higher concentrations of muscimol may abolish rhythmic respiratory discharge.

Bicarbonate efflux through $\mathrm{GABA}_{\mathrm{A}}$ receptor-coupled $\mathrm{Cl}^{-}$ channels can produce a considerable depolarizing shift of $E_{\text {GABA-A }}$ (Kaila, 1994). To test whether membrane diffusion of bicarbonate substantially contributed to $\mathrm{GABA}_{\mathrm{A}}$ receptormediated responses, the muscimol effect was tested in $\mathrm{CO}_{2} /$ $\mathrm{HCO}_{3}$-free bath solution (HEPES-buffered solution; $9 \mathrm{~mm}$ $\left.\left[\mathrm{K}^{+}\right]_{\mathrm{o}}\right)$ in $\mathrm{P} 2$ rats. Perfusion of $\mathrm{CO}_{2} / \mathrm{HCO}_{3}$-free HEPES-buffered saline did not affect $V_{\text {rest }}(-51 \pm 1.8 \mathrm{mV} ; n=4)$. Subsequent application of muscimol evoked a depolarization, and $E_{\mathrm{GABA}-\mathrm{A}}$ was $-46.2 \pm 2.0 \mathrm{mV}(n=4)$. Thus, as reported previously (Ritter and Zhang, 2000), $E_{\mathrm{GABA}-\mathrm{A}}$ observed using in vitro medullary slice preparations are essentially independent of bicarbonate conductances.

Taurine and glycine application

Figure 7 illustrates the influence of $\left[\mathrm{K}^{+}\right]_{\mathrm{o}}$ on taurine- and glycine-induced responses. The response to application of tau- 
A

Brainstem-spinal cord

B

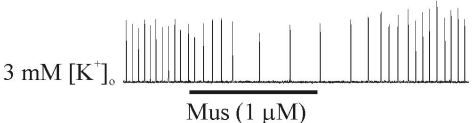

$6 \mathrm{mM}\left[\mathrm{K}^{+}\right]$

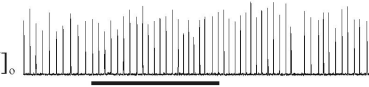

$\overline{\text { Mus }(1 \mu \mathrm{M})}$

$9 \mathrm{mM}\left[\mathrm{K}^{+}\right]$
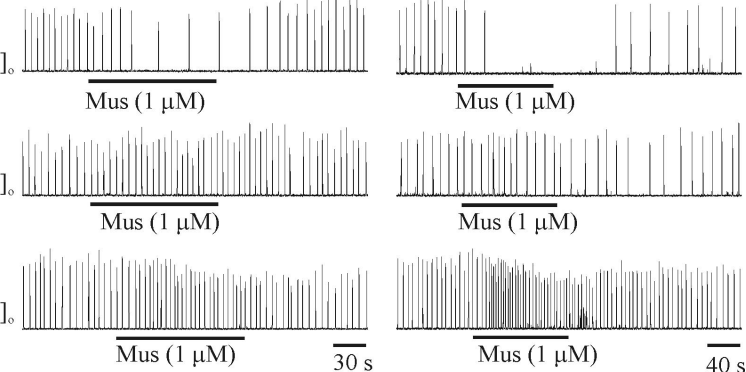

$\overline{\text { Mus }(1 \mu \mathrm{M})}$

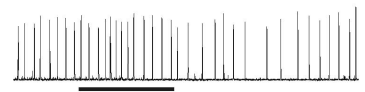

$\overline{\text { Mus }(1 \mu \mathrm{M})}$

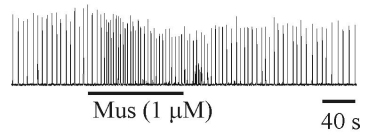

C

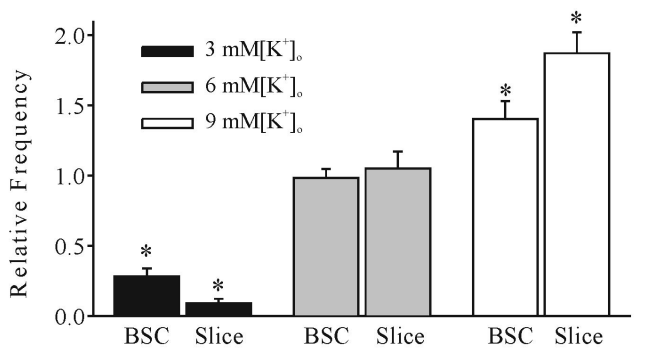

$\mathrm{D}$

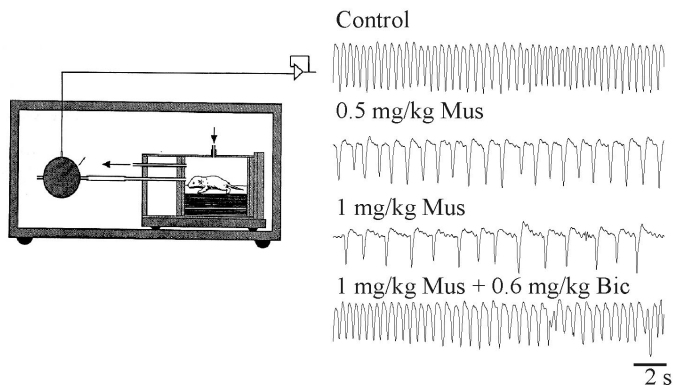

Figure 3. $\left[\mathrm{K}^{+}\right]_{0}$ dependency of responses to chloride-mediated conductances. The effects on respiratory frequency of muscimol in $\mathrm{P} 2$ brainstem-spinal cord $(\boldsymbol{A})$ and medullary slice $(\boldsymbol{B})$ preparations bathed in 3,6 , or $9 \mathrm{~mm}\left[\mathrm{~K}^{+}\right]_{0}$. Muscimol (1 $\mu \mathrm{m}$; Mus) decreased respiratory frequency when the brainstem-spinal cord or medullary slice preparations were superfused with $3 \mathrm{~mm}\left[\mathrm{~K}^{+}\right]_{0}$ bathing solution. In contrast, muscimol $(1 \mu \mathrm{m})$ increased respiratory frequency when the same preparation was superfused with $9 \mathrm{~mm}\left[\mathrm{~K}^{+}\right]_{0}$ bathing solution. Musci$\mathrm{mol}(1 \mu \mathrm{M})$ had no significant effect on respiratory frequency when the same preparation was superfused with $6 \mathrm{~mm}\left[\mathrm{~K}^{+}\right]_{0}$. C, Population data for responses to muscimol of brainstem-spinal cord (BSC) and medullary slice (Slice) preparations bathed in media with different $\left[\mathrm{K}^{+}\right]_{0} \cdot \mathbf{D}$, The effects of intraperitoneal administration of two doses of muscimol to an unanesthetized $P 2$ rat pup. Respiratory frequency was measured using a whole-body plethysmograph contained within an infant incubator for temperature control. The muscimol-induced suppression of respiratory frequency was antagonized by bicuculline (Bic). ${ }^{*} p<0.05$, significant difference relative to control.

rine $(5 \mathrm{~mm})$ of an I neuron in a P1 medullary slice bathed in 3 or $9 \mathrm{mM}\left[\mathrm{K}^{+}\right]_{\mathrm{o}}$ and $0.3 \mu \mathrm{M}$ TTX is shown in Figure $7 A$. $V_{\text {rest }}$ was -59 and $-51 \mathrm{mV}$ in 3 and $9 \mathrm{~mm}\left[\mathrm{~K}^{+}\right]_{\mathrm{o}}$, respectively. In $3 \mathrm{~mm}\left[\mathrm{~K}^{+}\right]_{\mathrm{o}}$, taurine caused an outward current from $V_{\mathrm{h}}$ of -25 and $-55 \mathrm{mV}$ and an inward current from a $V_{\mathrm{h}}$ of $-90 \mathrm{mV}$. In $9 \mathrm{mM}\left[\mathrm{K}^{+}\right]_{\mathrm{o}}$, taurine caused an outward current from a $V_{\mathrm{h}}$ of $-25 \mathrm{mV}$ and inward currents from $V_{\mathrm{h}}$ of -55 and $-90 \mathrm{mV}$. Current-voltage relationship of $I_{\text {taurine }}$ was fitted by a linear regression line (Fig. $7 B)$. The population data for the taurine-evoked responses in five I neurons are shown in Figure $7 C$. In $3 \mathrm{~mm}\left[\mathrm{~K}^{+}\right]_{\mathrm{o}}, V_{\text {rest }}$ and $E_{\text {taurine }}$ were $-58.8 \pm 1.6$ and $-63.5 \pm 2.3 \mathrm{mV}$, respectively. In 9 $\mathrm{mM}\left[\mathrm{K}^{+}\right]_{\mathrm{o}}, V_{\text {rest }}$ and $E_{\text {taurine }}$ were $-50.1 \pm 1.4$ and $-46.2 \pm 1.7$ $\mathrm{mV}$, respectively. Similarly, $E_{\text {glycine }}$ was $-46.5 \pm 1.5$ and $-64.2 \pm$ $2.2 \mathrm{mV}$ when preparations were perfused with 9 and $3 \mathrm{mM}\left[\mathrm{K}^{+}\right]_{\mathrm{o}}$,

A
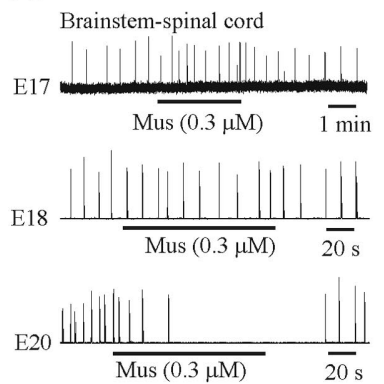

B

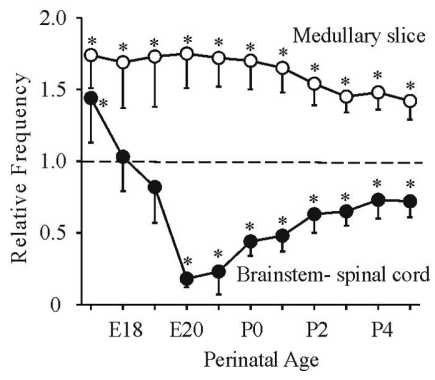

Figure 4. Age-dependent changes in the effects of chloride-mediated conductances. A, Rectified and integrated suction electrode recordings of XII nerve roots of brainstem-spinal cord preparations bathed in $3 \mathrm{~mm}\left[\mathrm{~K}^{+}\right]_{0}$ during the perinatal period. Muscimol (Mus) caused an increase, no significant change, and decrease of respiratory frequency at ages E17, E18, and E20 respectively. $\boldsymbol{B}$, Population data for changes in respiratory frequency relative to control of medullary slice and brainstem-spinal cord preparations in response to bath application of musci$\mathrm{mol}$. The transition from an excitatory to inhibitory action in brainstem-spinal cord preparations occurred at approximately E19. Respiratory frequency increased in medullary slice preparations bathed in $9 \mathrm{~mm}\left[\mathrm{~K}^{+}\right]_{0}$ at all ages. ${ }^{*} p<0.05$, significant difference relative to control.

\section{A}

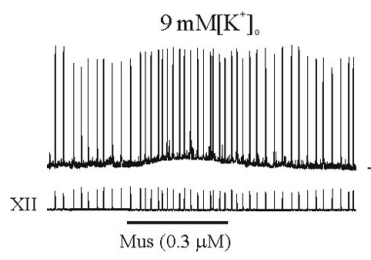

B

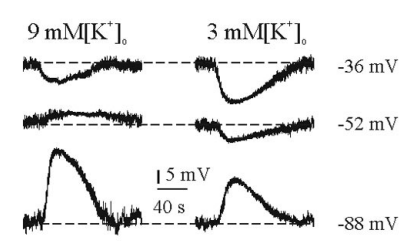

$\mathrm{D}$

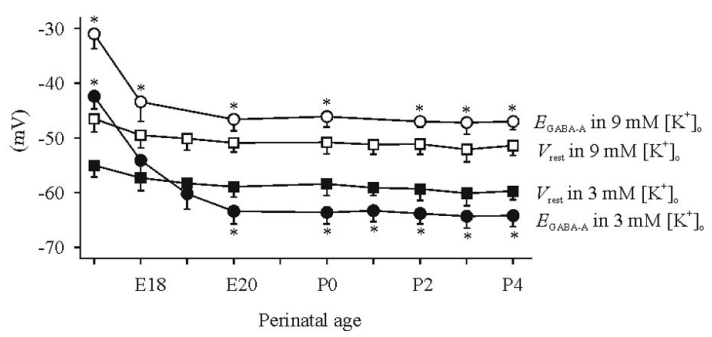

Figure 5. Influence of $\left[\mathrm{K}^{+}\right]_{0}$ on $V_{\text {rest }}$ and $E_{\mathrm{GABA}-\mathrm{A}} \cdot \boldsymbol{A}$, Top traces show perforated-patch recordings from an I neuron in a P2 medullary slice preparation bathed in 9 or $3 \mathrm{~mm}\left[\mathrm{~K}^{+}\right]_{0}$. Bottom traces are suction electrode recordings of XII nerve activity. $\ln 9 \mathrm{~mm}\left[\mathrm{~K}^{+}\right]_{0}, V_{\text {rest }}$ of the I neuron was $-52 \mathrm{mV}$, and muscimol (Mus) application caused a membrane depolarization and increase in respiratory frequency. After changing to $3 \mathrm{~mm}\left[\mathrm{~K}^{+}\right]_{0}, V_{\text {rest }}$ was $-61 \mathrm{mV}$, and muscimol caused a membrane hyperpolarization and decrease in respiratory frequency. $\boldsymbol{B}$, Perforated-patch recordings of an I neuron from a P1 medullary slice preparation in the presence of TTX $(0.3 \mu \mathrm{m})$. Recordings show the responses to bath-applied muscimol while the $V_{\mathrm{m}}$ was changed by injection of direct current. $C$, Linear regression line based on data shown in $\boldsymbol{B}$. There was an $\sim 17 \mathrm{mV}$ depolarizing shift in $E_{\text {GABA-A }}$ when the bathing medium was changed from 3 to $9 \mathrm{~mm}\left[\mathrm{~K}^{+}\right]_{0}$. D, Summary of $V_{\text {rest }}$ and $E_{\text {GABA-A }}$ for all I neurons recorded from at different perinatal ages in medullary slice preparations bathed in 3 or $9 \mathrm{~mm}\left[\mathrm{~K}^{+}\right]_{0} \cdot{ }^{*} p<0.05$, significant difference between $V_{\text {rest }}$ and $E_{\text {GABA-A }}(n=4-7)$. 
respectively $(n=4)$ (Fig. $7 D)$. There were no significant differences in the reversal potential among taurine-, glycine-, or muscimol-induced responses.

Influence of $\left[\mathrm{K}^{+}\right]_{\mathrm{o}}$ on $E_{\mathrm{IPSP}}$ IPSP were studied from recordings of expiratory (E) neurons in neonatal medullary slice preparations. Figure $8 \mathrm{~A}$ shows recordings from an $\mathrm{E}$ cell in a $\mathrm{P} 1$ rat preparation using both gramicidin perforatedpatch and conventional whole-cell recordings. $V_{\text {rest }}$ was $-49 \mathrm{mV}$ with both recording techniques. The IPSPs during the inspiratory phase are accentuated during whole-cell recordings when $\left[\mathrm{Cl}^{-}\right]_{\mathrm{i}}$ is decreased by dialysis of the pipette solution. Figure $8 B$ shows that strychnine ( 1 $\mu \mathrm{M})$, but not bicuculline $(30 \mu \mathrm{M})$, blocked inspiratory-related IPSPs of an E neuron recorded from a $\mathrm{P} 1$ rat with the conventional whole-cell recording. This observation is consistent with the report by Shao and Feldman (1997) showing glycinergicmediated IPSPs in the preBötC. $E_{\mathrm{IPSP}}$ from a tonic $\mathrm{E}$ cell with perforated-patch recordings was measured in $9 \mathrm{~mm}$ (Fig. $8 C$ ) and $3 \mathrm{~mm}($ Fig. $8 D)\left[\mathrm{K}^{+}\right]_{\mathrm{o}} . V_{\text {rest }}$ and $E_{\text {IPSP }}$ in $9 \mathrm{~mm}\left[\mathrm{~K}^{+}\right]_{\mathrm{o}}$ was $-51 \mathrm{mV}$ and between -42 and $-51 \mathrm{mV}$, respectively. $V_{\text {rest }}$ and $E_{\text {IPSP }}$ in $3 \mathrm{~mm}\left[\mathrm{~K}^{+}\right]_{\mathrm{o}}$ was $-61 \mathrm{mV}$ and between -61 and $-70 \mathrm{mV}$, respectively.

Figure $8 E$ shows the linear regression line calculated for the amplitudes of IPSPs from Figure 8, $C$ and $D$. Population data for five E neurons is presented in Figure $8 F$. Similar to that observed from I cells, there was an overall shift in $E_{\mathrm{IPSP}}$ of $\sim 18 \mathrm{mV}$ in the hyperpolarizing direction when the bathing solution was switched from 9 to $3 \mathrm{~mm}\left[\mathrm{~K}^{+}\right]_{\mathrm{o}}$.

\section{Perturbations of chloride transporter function}

Neuronal $\left[\mathrm{Cl}^{-}\right]_{\mathrm{i}}$ is regulated by the action of two principal cation-chloride cotransporters. Typically, the $\mathrm{Na}-\mathrm{K}-2 \mathrm{Cl}$ cotransporter (NKCC1) raises $\left[\mathrm{Cl}^{-}\right]_{\mathrm{i}}$ and the $\mathrm{K}-\mathrm{Cl}$ cotransporter (KCC2) lowers $\left[\mathrm{Cl}^{-}\right]_{\mathrm{i}}$ (Kaila, 1994). We examined how perturbation of each of these chloride cotransporters affected muscimol-induced responses of respiratory neurons in medullary slice preparations of varying perinatal age and $\left[\mathrm{K}^{+}\right]_{\mathrm{o}}$.

\section{Effects of removing extracellular sodium ions}

The NKCC1 transporter is expressed early in neuronal development and plays a role in increasing $\left[\mathrm{Cl}^{-}\right]_{\mathrm{i}}$ (Payne et al., 2003). We impaired the function of the NKCC1 transporter by replacing $\left[\mathrm{Na}^{+}\right]_{\mathrm{o}}$ with choline. All recordings were performed in $3 \mathrm{~mm}$ $\left[\mathrm{K}^{+}\right]_{\mathrm{o}}$. Figure $9 A$ shows that application of muscimol ( $3 \mathrm{~mm}$ for $30 \mathrm{~s}$ ) induces a depolarization from $V_{\mathrm{h}}$ of -50 and $-65 \mathrm{mV}$ in a perforated-patch recording of an I neuron at E17 in control conditions (left panels). $E_{\text {GABA-A }}$ was shifted close to $V_{\text {rest }}$ after removal of extracellular $\mathrm{Na}^{+}$(middle panels). The effect was reversible after return to control solution (right panels). Population data from four I neurons are shown in Figure 9 C. In contrast, we did not observe a significant change in $E_{\mathrm{GABA}-\mathrm{A}}$ from ages P1-P3 after replacing $\left[\mathrm{Na}^{+}\right]_{0}$ with choline (data not shown).

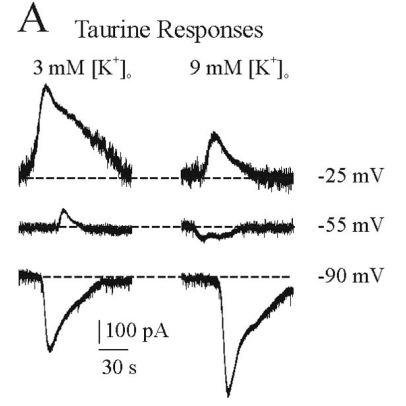

B Taurine Response

C Taurine Response
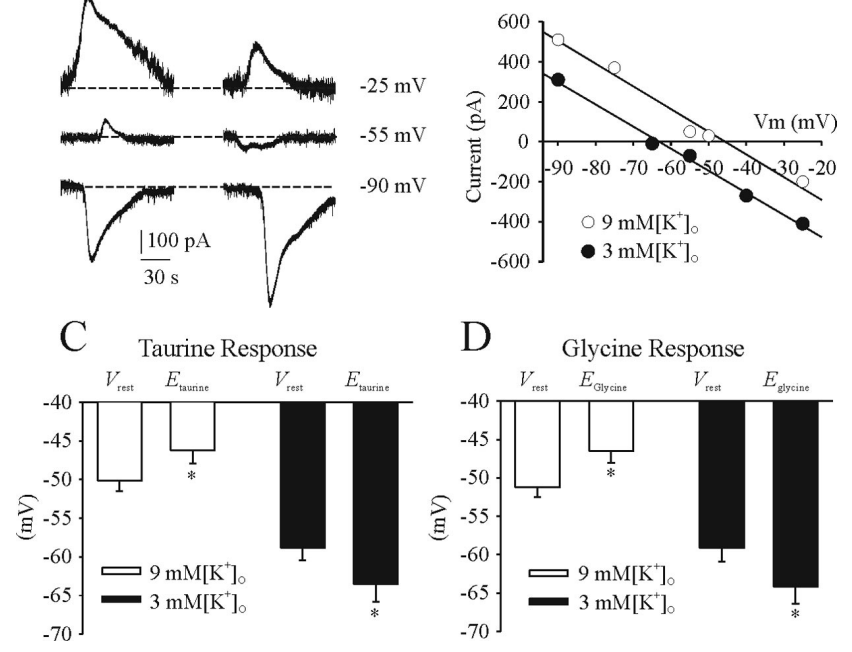

Figure 7. Influence of $\left[\mathrm{K}^{+}\right]_{0}$ on $V_{\text {rest }}, E_{\text {taurine, }}$ and $E_{\text {glycine. }} A$, Perforated-patch recordings of an I neuron from a P1 medullary slice preparation in the presence of TTX $(0.3 \mu \mathrm{M})$. Recordings show the responses to bath-applied taurine in the voltage-clamp mode. $\boldsymbol{B}$, Linear regression line based on data shown in $A$. C, Summary of $V_{\text {rest }}$ and $E_{\text {taurine }}$ for all I neurons recorded from P1 medullary slice preparations bathed in 3 or $9 \mathrm{~mm}\left[K^{+}\right]_{0} . D$, Summary of $V_{\text {rest }}$ and $E_{\text {glycine }}$ for all Ineurons recorded from $\mathrm{P} 1$ medullary slice preparations bathed in 3 or $9 \mathrm{~mm}\left[\mathrm{~K}^{+}\right]_{0}{ }^{*}{ }^{*} p<0.05$, significant difference between $V_{\text {rest }}$ and $E_{\text {taurine }}$ or $E_{\text {glycine. }}$.

\section{Effects of bumetanide application}

Administration of muscimol $(0.3 \mu \mathrm{M})$ caused an increase in the respiratory frequency generated by E17 brainstem-spinal cord and medullary slice preparations (Fig. 10A, top traces). The 

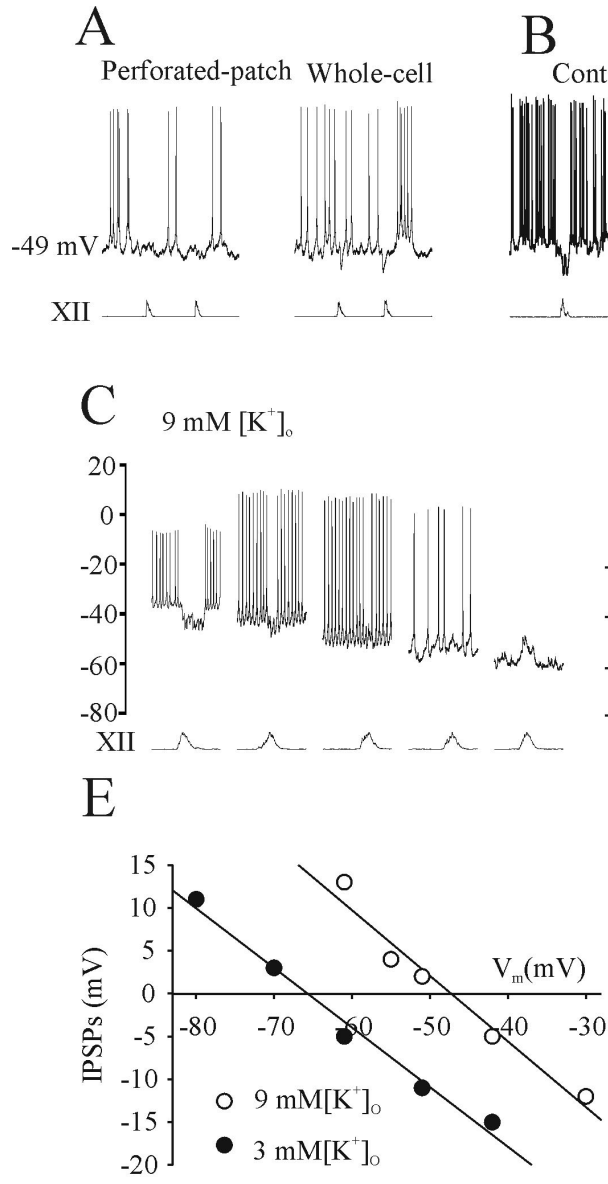

Figure 8. Characterization of endogenous chloride-mediated inhibition in expiratory neurons. A, Perforated-patch and conventional whole-cell recordings of an $\mathrm{E}$ cell in a $\mathrm{P} 1$ medullary slice preparation bathed in $9 \mathrm{~mm}\left[\mathrm{~K}^{+}\right]_{0} \cdot V_{\text {rest }}$ was $-49 \mathrm{mV}$ with both recording techniques. $\boldsymbol{B}$, Conventional whole-cell recording from another Eneuron in a P1 medullary slice preparation. Strychnine ( $1 \mu \mathrm{m}$; Str), but not bicuculline (30 $\mu \mathrm{m} ; \mathrm{Bic}$ ), blocked IPSPs during the inspiratory phase. C, Perforated-patch recording of an $\mathrm{E}$ neuron in a $\mathrm{P} 1$ medullary slice preparation bathed in $9 \mathrm{~mm}\left[\mathrm{~K}^{+}\right]_{0}$ held at various $V_{\mathrm{m}}$ values. $V_{\text {rest }}$ was $-51 \mathrm{mV}$, and the $E_{\text {IPSP }}$ was between -42 and $-51 \mathrm{mV}$. D, When superfused with $3 \mathrm{~mm}\left[\mathrm{~K}^{+}\right]_{0}, V_{\text {rest }}$ was $-61 \mathrm{mV}$, and $E_{\text {IPSP }}$ was between -61 and $-70 \mathrm{mV}$. $\boldsymbol{E}$, Linear regression line was calculated for the amplitudes of IPSPs at different levels from $\boldsymbol{C}$ and $\boldsymbol{D}$. $\boldsymbol{F}$, Summary of $V_{\text {rest }}$ and $E_{\mathrm{IPSP}}$ for all E neurons recorded from medullary slice preparations bathed in 3 or $9 \mathrm{~mm}\left[\mathrm{~K}^{+}\right]_{0}$ (each data point is from $4-5 \mathrm{E}$ neurons). ${ }^{*} p<0.05$, significant difference between $V_{\text {rest }}$ and $E_{\text {IPSP }}$.

muscimol-induced excitatory effects were blocked by $20-40 \mathrm{~min}$ bath application of bumetanide $(10 \mu \mathrm{M})$, a specific inhibitor of the NKCC1 cotransporter (Fig. 10A, bottom traces). At P2, the respiratory frequency generated by brainstem-spinal cord and medullary slice preparations was decreased and increased by application of muscimol $(0.3 \mu \mathrm{M})$, respectively (Fig. $10 \mathrm{~B}$, top traces). Neither of the muscimol-induced changes was modified by bumetanide $(10 \mu \mathrm{M})$ (Fig. $10 \mathrm{~B}$, bottom traces). Population data for the actions of muscimol and muscimol plus bumetanide for both types of E17 in vitro preparations $(n=5)$ are presented in Figure 10C. Perforated-patch recordings were made from six I neurons in E17 medullary slice preparations bathed in $3 \mathrm{~mm}$ $\left[\mathrm{K}^{+}\right]_{\mathrm{o}}$ in the absence and presence of bumetanide $(10 \mu \mathrm{M})$. After exposure to bumetanide, $E_{\mathrm{GABA}-\mathrm{A}}$ shifted from $-42.3 \pm 2.5$ to $-51.8 \pm 3.7 \mathrm{mV}$ without a significant change in $V_{\text {rest }}$ (Fig. $10 \mathrm{D}$ ).

\section{Effects of furosemide application}

Application of furosemide was used to block the KCC2 cotransporter in brainstem-spinal cord and medullary slice preparations at P1-P2. The muscimol-induced suppression of respiratory frequency generated in the brainstem-spinal cord was blocked after $25 \mathrm{~min}$ exposure to furosemide $(1 \mu \mathrm{M})$ (Fig. 11A). The muscimol-induced depolarization of an I neuron and increase in respiratory frequency in a medullary slice preparation bathed in $9 \mathrm{~mm}\left[\mathrm{~K}^{+}\right]_{\mathrm{o}}$ was attenuated by furosemide $(1 \mathrm{~mm})$ (Fig. $11 \mathrm{~B})$. The population data for the effects of muscimol and muscimol plus furosemide on respiratory frequency generated by neonatal in vitro preparations are shown in Figure $11 C$. The population data showing the effects of furosemide on six I neurons in presented in Figure $11 D$. Furosemide did not significantly affect $V_{\text {rest }}$ of neurons bathed in either 3 or $9 \mathrm{~mm}\left[\mathrm{~K}^{+}\right]_{\mathrm{o}}$. However, furosemide significantly shifted $E_{\mathrm{GABA}-\mathrm{A}}$ from $-46.2 \pm 2.0$ to $-49.5 \pm 2.3 \mathrm{mV}$ and $-64.1 \pm 1.5$ to $-59.6 \pm 2.7 \mathrm{mV}$ in 9 and 3 $\mathrm{mM}\left[\mathrm{K}^{+}\right]_{\mathrm{o}}$, respectively. The muscimol $(0.3 \mu \mathrm{M})$-induced increase of respiratory frequency at E17 persisted in the presence of furosemide (1 mM; data not shown). It should be noted that furosemide also affects NKCC1 cotransporter function (Gillen et al., 1996; Payne et al., 2003). However, as discussed above, a perturbation of the NKCC1 transporter with removal of $\left[\mathrm{Na}^{+}\right]_{\mathrm{o}}$ or bumetanide did not affect muscimol-induced responses during the postnatal period, and thus the data can be explained by a specific interference with KCC2 function.

\section{Discussion}

These data demonstrate the agedependent changes in the effects of chloride-mediated conductances on respiratory frequency from the time of inception of fetal inspiratory drive through to the newborn period. The transition from an excitatory to inhibitory effect on respiratory neurons and rhythmogenesis occurred at approximately E19. GABA, glycine, and taurine all suppressed respiratory frequency by birth. The actions of chloride-mediated conductances on respiratory activity are profoundly affected by $\left[\mathrm{K}^{+}\right]_{0}$, which explains some of the discrepancies from past studies using different in vitro models.

\section{Dependence of chloride-mediated conductances on $\left[\mathrm{K}^{+}\right]_{\mathrm{o}}$}

Our initial observation that muscimol, glycine, and taurine caused contrasting changes in respiratory frequency between neonatal brainstem-spinal cord and medullary slice preparations was unexpected. Subsequent experimentation demonstrated that the apparent discrepancy could be accounted for by different levels of $\left[\mathrm{K}^{+}\right]_{\mathrm{o}}$ in the media used to bathe the two types of in vitro preparations. Specifically, $\left[\mathrm{K}^{+}\right]_{\mathrm{o}}$ influenced the function of cotransporters that determine transmembrane $\mathrm{Cl}^{-}$gradients (discussed below). Perforated-patch recordings from both I and $\mathrm{E}$ neurons demonstrated that increasing $\left[\mathrm{K}^{+}\right]_{\mathrm{o}}$ from 3 to $9 \mathrm{mM}$ results in an $\sim 8 \mathrm{mV}$ depolarization of $V_{\text {rest }}$ and a $15-20 \mathrm{mV}$ depolarization (E20 to P4) of the reversal potential for chloridemediated conductances. Thus, elevating the $\left[\mathrm{K}^{+}\right]_{\mathrm{o}}$ to $9 \mathrm{~mm}$ in either type of postnatal in vitro preparation caused an efflux 
A

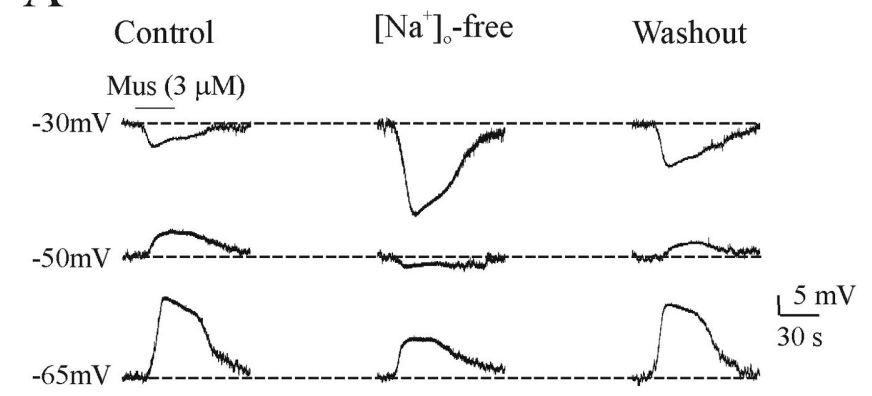

$\mathrm{B}$

$\mathrm{C}$
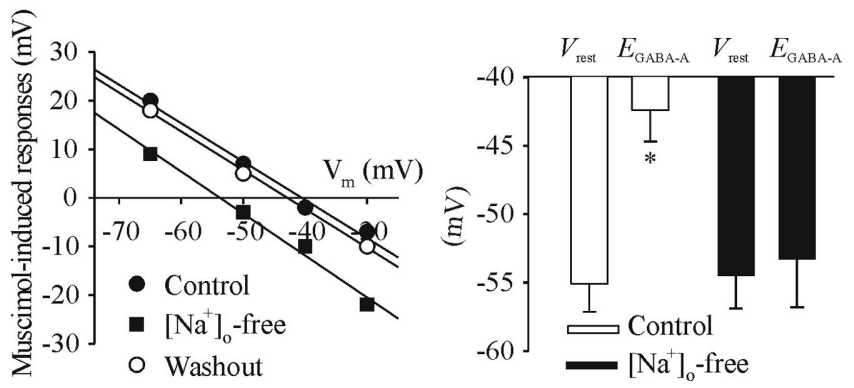

Figure 9. Effects of perturbing NKCC1 transporter function by removing $\left[\mathrm{Na}^{+}\right]_{0} . \boldsymbol{A}$, Perforated-patch recordings of an I neuron from an E17 medullary slice preparation bathed in 3 $\mathrm{mm}\left[\mathrm{K}^{+}\right]_{0}$ in the presence of TTX $(0.3 \mu \mathrm{m})$. Muscimol (Mus) was administered to bathing medium containing either control levels of $\left[\mathrm{Na}^{+}\right]_{0}$ or $0\left[\mathrm{Na}^{+}\right]_{0}$ (replaced with choline) while $V_{m}$ was changed by injection of direct current. Perturbation of the NKCC1 pump by $\left[\mathrm{Na}^{+}\right]_{0}$ shifted $E_{\text {GABA-A }}$ to a more hyperpolarized value. $B$, Linear regression line from recordings in $A$. $C$, Summary of $V_{\text {rest }}$ and $E_{\text {GABA-A }}$ for all neurons recorded from E17 medullary slice preparations bathed in control or $0\left[\mathrm{Na}^{+}\right]_{0} \cdot{ }^{*} p<0.05$, significant difference between $V_{\text {rest }}$ and $E_{\mathrm{GABA}-\mathrm{A}}$.

rather than an influx of $\mathrm{Cl}^{-}$seen with $3 \mathrm{~mm}\left[\mathrm{~K}^{+}\right]_{\mathrm{o}}$ in response to $\mathrm{GABA}_{\mathrm{A}}$ or glycine receptor agonists. These data can explain the inconsistencies from past studies examining the actions of chloride-mediated conductances on respiratory rhythm in neonatal rodent in vitro preparations. Brockhaus and Ballanyi (1998) reported predominantly hyperpolarizing actions of $\mathrm{GABA}_{\mathrm{A}}$ - and glycine receptor-mediated conductances in newborn brainstemspinal cord preparations (bathed in $3 \mathrm{~mm}\left[\mathrm{~K}^{+}\right]_{\mathrm{o}}$ ). Furthermore, Fregosi et al., (2004) reported a depression of respiratory frequency generated by brainstem-spinal cord preparations in response to $\mathrm{GABA}_{\mathrm{A}}$ receptor activation. In contrast, Ritter and Zhang (2000) reported predominantly depolarizing actions in medullary slice preparations derived from newborn mice (bathed in $9 \mathrm{mM}\left[\mathrm{K}^{+}\right]_{\mathrm{o}}$ ). We propose that differences in results and thus interpretation of the actions of chloride-mediated conductance were attributable in part to altered $\left[\mathrm{K}^{+}\right]_{\mathrm{o}}$ conditions.

\section{Dependence of chloride-mediated conductances on perinatal stage of development}

Respiratory rhythmogenesis within the preBötC commences on E17 in the rat (Pagliardini et al., 2003). Before E17, there is a robust endogenous embryonic rhythmic activity present throughout much of the developing neuraxis, including the ventrolateral medulla (Greer et al., 1992; Ren and Greer, 2003; Ren et al., 2006). GABA and glycine act as excitatory neurotransmitters promoting the emergence of embryonic rhythms (Ren and Greer, 2003). Data from this study demonstrates that agonists to $\mathrm{GABA}_{\mathrm{A}}$ and glycine receptors also lead to a depolarization of I neurons
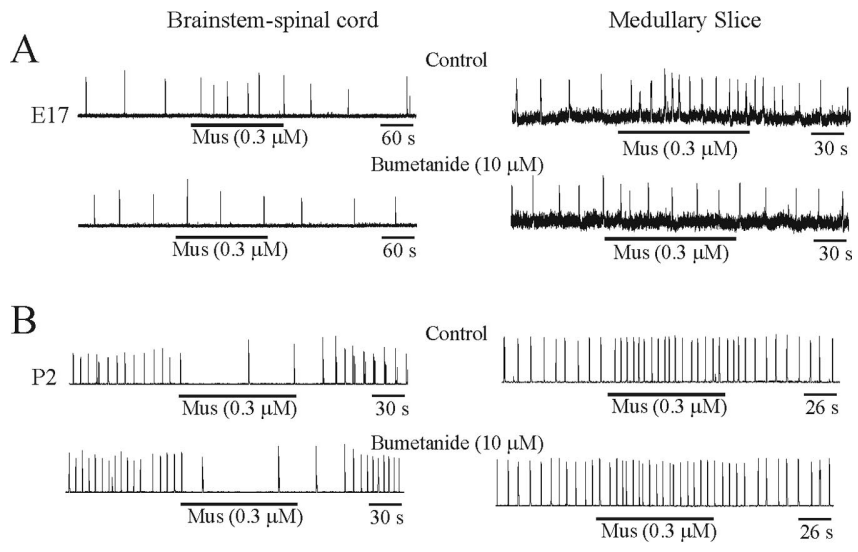

C

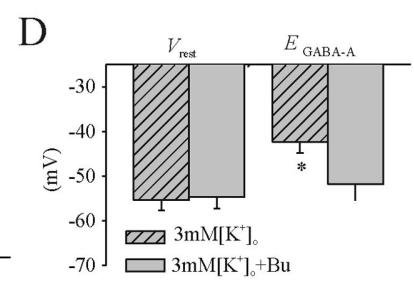

Figure 10. Effects of the NKCC1 blocker bumetanide. $\boldsymbol{A}$, Rectified and integrated suction electrode recordings of $(4$ ventral roots (brainstem-spinal cord) and XII nerve roots (medullary slice) at E17. Muscimol (Mus) was added to preparations bathed in control solution and after 30 min of bumetanide application. In the presence of NKCC 1 blocker, the increase in respiratory frequency caused by muscimol was blocked. $\boldsymbol{B}$, Similar recording and experimental paradigm as in $\boldsymbol{A}$ but at age P2. The responses of both types of in vitro preparations were not significantly affected by bumetanide. C, Population data for brainstem-spinal cord and medullary slice preparations showing changes in frequency of respiration relative to control in response to muscimol or muscimol plus bumetanide (Bu) administration. D, Summary of $V_{\text {rest }}$ and $E_{G A B A-A}$ data from gramicidin perforated-patch recordings of I neurons in medullary slices (E17) in $3 \mathrm{mM}$ $\left[\mathrm{K}^{+}\right]_{0}$ in the presence of TTX $(0.3 \mu \mathrm{m})$, with and without bumetanide. $V_{\text {rest }}$ was not affected by bumetanide, but $E_{G A B A-A}$ was shifted to more hyperpolarizing values in $E 17$ in vitro preparations. ${ }^{*} p<0.05$, significant difference between muscimol-induced changes in breathing frequency with and without bumetanide $(\boldsymbol{C})$ and $V_{\text {rest }}$ and $E_{\text {GABA-A }}(\boldsymbol{D})$.

and an increase in respiratory frequency at the inception of fetal respiratory drive. The switch from excitatory to inhibitory actions of chloride-mediated conductances is at approximately E19. By E20-E21, activation of $\mathrm{GABA}_{\mathrm{A}}$ or glycine receptors (via glycine or taurine) results in a hyperpolarization of respiratory neurons and depression of respiratory frequency in vitro under typical physiological levels of $\left[\mathrm{K}^{+}\right]_{\mathrm{o}}$. The in vivo data demonstrating a suppression of respiratory rhythm after intraperitoneal administration of muscimol to rat pups are consistent with those data.

Functionally, the depolarization of respiratory neurons at early stages of development will remove NMDA voltagedependent $\mathrm{Mg}^{2+}$ block and thus enhance glutamate-mediated depolarization and rise of $\left[\mathrm{Ca}^{2+}\right]_{\mathrm{i}}$ (Rohrbough and Spitzer, 1996; Ziskind-Conhaim, 1998). In turn, elevated $\left[\mathrm{Ca}^{2+}\right]_{\mathrm{i}}$ regulates neurite outgrowth, gene expression, transmitter release, and local receptor protein aggregation (Yuste and Katz, 1991; Ben Ari et al., 1997). Collectively, these factors could facilitate the marked phenotypic changes of electrophysiological and firing properties of ventral respiratory group neurons that occur between E17 and E19 (DiPasquale et al., 1996). Later in gestation and in the newborn period, elevated levels of GABA, glycine, or taurine (e.g., in response to hypoxia) within the preBötC will result in a suppression of respiratory frequency. 


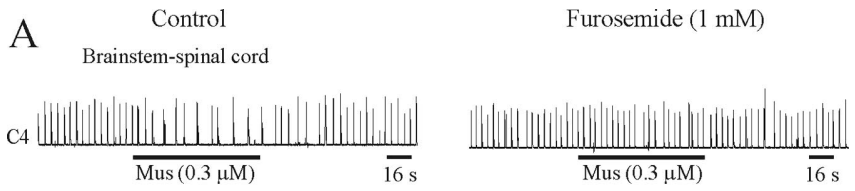

B

Medullary slice

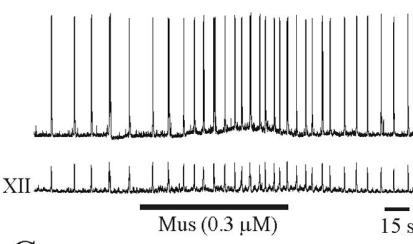

C

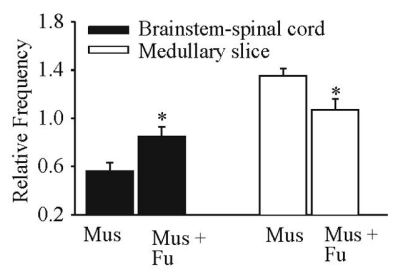

$\mathrm{D}$

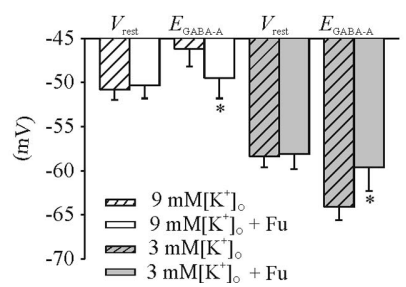

Figure 11. Effects of the KCC2 blocker furosemide. $\boldsymbol{A}$, Rectified and integrated suction electrode recordings of $(4$ ventral roots in a P1 brainstem-spinal cord preparation. The muscimolinduced (Mus) decrease of respiratory rhythm (left) was diminished after 30 min of furosemide application (right). $\boldsymbol{B}$, Perforated-patch recording of an I neuron (top) and XII nerve root recording (bottom) from a P1 medullary slice preparation. The muscimol-induced membrane depolarization and increase of respiratory rhythm (left) were diminished in the presence of furosemide (right). C, Population data for brainstem-spinal cord and medullary slice preparations showing changes in respiratory frequency relative to control in response to muscimol or muscimol plus furosemide $(\mathrm{Fu})$ administration. $\boldsymbol{D}$, Summary of $V_{\text {rest }}$ and $E_{\mathrm{GABA}-\mathrm{A}}$ data from perforated-patch recordings of I neurons in medullary slices (P1-P2) in 3 or $9 \mathrm{~mm}\left[\mathrm{~K}^{+}\right]_{0}$, with and without furosemide. $V_{\text {rest }}$ was not affected by furosemide, but $E_{\mathrm{GABA}-\mathrm{A}}$ was shifted toward $V_{\text {rest }}$ in both types of postnatal in vitro preparations. ${ }^{*} p<0.05$, significant difference between muscimol-induced changes in breathing frequency $(\boldsymbol{C})$ and $E_{\mathrm{GABA}-\mathrm{A}}(\boldsymbol{D})$ with and without furosemide.

\section{Dependence of chloride-mediated conductances on chloride cotransporter function}

Early in fetal development, the NKCC1 cotransporter is expressed at relatively high levels, and thus there is an elevated intracellular $\left[\mathrm{Cl}^{-}\right]$relative to mature neurons (Kaila, 1994). The increased expression of the KCC2 cotransporter with perinatal age leads to the extrusion of $\mathrm{Cl}^{-}$from the cytoplasm and thus establishment of an chloride equilibrium potential $\left(E_{\mathrm{Cl}-}\right)$ that is hyperpolarized from $V_{\text {rest }}$ (Rivera et al., 1999). Perturbation of NKCC1 function with $\left[\mathrm{Na}^{+}\right]_{\mathrm{o}}$-free solution and bumetanide shifted $E_{\mathrm{Cl}}$ to hyperpolarized values in pre-E18 in vitro preparations. The shift in $E_{\mathrm{Cl}-}$ was sufficient to reverse the normal muscimol-induced increase in respiratory frequency. Perturbations of KCC2 function with furosemide had no significant effect before E18. Those data are consistent with the dominance of NKCC1 function that results in $E_{\mathrm{Cl}-}$ at values less negative than $V_{\text {rest }}$. In contrast, perturbation of KCC2 function with furosemide in neonatal preparations resulted in the block of muscimol-induced decrease in respiratory frequency in the brainstem-spinal cord preparations and hyperpolarization of $E_{\mathrm{Cl}-}$ in the medullary slice perfused with $3 \mathrm{~mm}\left[\mathrm{~K}^{+}\right]_{\mathrm{o}}$ solution. Block of NKCC1 function had no significant effect. Thus, the function of KCC2 extrusion of $\mathrm{Cl}^{-}$dominated control of $E_{\mathrm{Cl}}$ postnatally. Furthermore, perturbation of KCC2 function with furosemide in neonatal preparations resulted in the block of muscimol-induced increase in respiratory frequency and depo- larization of $E_{\mathrm{Cl}-}$ in the medullary slice perfused with $9 \mathrm{~mm}$ $\left[\mathrm{K}^{+}\right]_{\mathrm{o}}$ solution. These data indicate that changes in KCC2 function in elevated $\left[\mathrm{K}^{+}\right]_{\mathrm{o}}$ were responsible for a significant component of the differential responses to chloride-mediated conductances observed in bathing mediums with different $\left[\mathrm{K}^{+}\right]_{\mathrm{o}}$. As demonstrated previously in neocortical pyramidal neurons, there

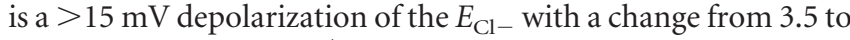
$10 \mathrm{~mm}$ extracellular $\left[\mathrm{K}^{+}\right]$(DeFazio et al., 2000). These results confirmed the observation that KCC2 could extrude or accumulate $\mathrm{Cl}^{-}$depending on $\left[\mathrm{K}^{+}\right]_{\mathrm{o}}$ (Payne 1997).

\section{Summary}

Respiratory neurons in the ventrolateral medulla are depolarized by chloride-mediated conductances before and at the time of inception of respiratory rhythmogenesis in the fetal rat. By E19, chloride-mediated conductances induce a hyperpolarization of respiratory membrane potential and suppression of respiratory frequency. The action of chloride-mediated conductances is determined by the ontogenesis of chloride cotransporters. The function of chloride cotransporters is strongly modulated by $\left[\mathrm{K}^{+}\right]_{\mathrm{o}}$, and this must be considered when evaluating responses observed using in vitro perinatal preparations.

\section{References}

Angulo y González AW (1932) The prenatal growth of the albino rat. Anat Rec 52:117-138.

Ballanyi K (2004) Neuromodulation of the perinatal respiratory network. Curr Neuropharmacol 2:221-243.

Ben Ari Y, Khazipo VR, Leinekugel X, Caillard O, Gaiarsa JL (1997) GABA $_{A}$, NMDA and AMPA receptors: a developmentally regulated "menage a trois." Trends Neurosci 20:523-529.

Bonham AC (1995) Neurotransmitters in the CNS control of breathing. Respir Physiol 101:219-230.

Brockhaus J, Ballanyi K (1998) Synaptic inhibition in the isolated respiratory network of neonatal rats. Eur J Neurosci 10:3823-3839.

DeFazio RA, Keros S, Quick MW, Hablitz JJ (2000) Potassium-coupled chloride cotransport controls intracellular chloride in rat neocortical pyramidal neurons. J Neurosci 20:8069-8076.

DiPasquale E, Tell F, Monteau R, Hilaire G (1996) Perinatal developmental changes in respiratory activity of medullary and spinal neurons: an in vitro study on feotal and newborn rats. Dev Brain Res 91:121-130.

Fregosi RF, Luo Z, Iizuka M (2004) GABA $_{\mathrm{A}}$ receptors mediate postnatal depression of respiratory frequency by barbiturates. Respir Physiol Neurobiol 140:219-230.

Gillen CM, Brill S, Payne JA, Forbush B (1996) Molecular cloning and functional expression of the $\mathrm{K}-\mathrm{Cl}$ cotransporter from rabbit, rat, and human. A new member of the cation-chloride cotransporter family. J Biol Chem 271:16237-16244.

Greer JJ, Smith JC, Feldman JL (1992) Generation of respiratory and locomotor patterns by an in vitro brainstem-spinal cord fetal rat preparation. J Neurophysiol 67:996-999.

Greer JJ, Allan DW, Martin-Caraballo M, Lemke RP (1999) An overview of phrenic nerve and diaphragm muscle development in the perinatal rat. J Appl Physiol 86:779-786.

Harding R, Hooper SB (1996) Regulation of lung expansion and lung growth before birth. J Appl Physiol 81:209-224.

Holtman JR, Buller AL, Taveira Da Silva AM, Hamosh P, Gillis RA (1983) Respiratory depression produced by centrally administered taurine in the cat. Life Sci 32:2313-2320.

Hoop B, Beagle JL, Maher TJ, Kazemi H (1999) Brainstem amino acid neurotransmitters and hypoxic ventilatory response. Respir Physiol 118:117-129.

Jansen AH, Chernick V (1991) Feotal breathing and development of control of breathing. J Appl Physiol 70:1431-1446.

Johnson SM, Smith JC, Feldman JL (1996) Modulation of respiratory rhythm in vitro: role of Gi/o protein-mediated mechanisms. J Appl Physiol 80:2120-2133.

Kaila K (1994) Ionic basis of $\mathrm{GABA}_{\mathrm{A}}$ receptor channel function in the nervous system. Prog Neurobiol 42:489-537. 
Kitterman JA (1988) Physiological factors in fetal lung growth. Can J Physiol Pharmacol 66:1122-1128.

Kobayashi K, Lemke RP, Greer JJ (2001) Ultrasound measurements of fetal breathing movements in the rat. J Appl Physiol 91:316-320.

Kyrozis A, Reichling DB (1995) Perforated-patch recording with gramicidin avoids artifactual changes in intracellular chloride concentration. J Neurosci Methods 57:27-35.

Marty A, Neher E (1985) Potassium channels in cultured bovine adrenal chromaffin cells. J Physiol (Lond) 367:117-141.

Pagliardini S, Ren J, Greer JJ (2003) Ontogeny of the pre-Botzinger complex in perinatal rats. J Neurosci 23:9575-9584.

Payne JA (1997) Functional characterization of the neuronal-specific K-Cl cotransporter: implications for $\left[\mathrm{K}^{+}\right]_{\mathrm{o}}$ regulation. Am J Physiol 273:C1516-C1525.

Payne JA, Rivera C, Voipio j, Kaila K (2003) Cation-chloride cotransporters in neuronal communication, development and trauma. Trends Neurosci 26:199-206.

Rekling JC, Feldman JL (1998) PreBotzinger complex and pacemaker neurons: hypothesized site and kernel for respiratory rhythm generation. Annu Rev Physiol 60:385-405.

Ren J, Greer JJ (2003) Ontogeny of rhythmic motor patterns generated in the embryonic rat spinal cord. J Neurophysiol 89:1187-1195.

Ren J, Momose-Sato Y, Sato K, Greer JJ (2006) Rhythmic neuronal discharge in the medulla and spinal cord of fetal rats in the absence of synaptic transmission. J Neurophysiol 95:527-534.

Ritter B, Zhang W (2000) Early postnatal maturation of $\mathrm{GABA}_{\mathrm{A}}$-mediated inhibition in the brainstem respiratory rhythm-generating network of the mouse. Eur J Neurosci 12:2975-2984.

Rivera C, Voipio J, Payne JA, Ruusuvuori E, Lahtinen H, Lamsa K, Pirvola U, Saarma M, Kaila K (1999) $\mathrm{The}^{+} / \mathrm{Cl}^{-}$cotransporter KCC2 tenders GABA hyperpolarizing during neuronal maturation. Nature 397:251-255.

Rohrbough J, Spitzer NC (1996) Regulation of intracellular $\mathrm{Cl}^{-}$levels by $\mathrm{Na}^{+}$-dependent $\mathrm{Cl}^{-}$cotransport distinguishes depolarizing from hyperpolarizing $\mathrm{GABA}_{\mathrm{A}}$ receptor-mediated responses in spinal neurons. J Neurosci 16:82-91.

Shao XM, Feldman JL (1997) Respiratory rhythm generation and synaptic inhibition of expiratory neurons in pre-Botzinger complex: differential roles of glycinergic and GABAergic neural transmission. J Neurophysiol 77:1853-1860.

Smith JC, Greer JJ, Liu GS, Feldman JL (1990) Neural mechanisms generating respiratory pattern in mammalian brain stem-spinal cord in vitro. I. Spatiotemporal patterns of motor and medullary neuron activity. J Neurophysiol 64:1149-1169.

Smith JC, Ellenberger HH, Ballanyi K, Richter DW, Feldman JL (1991) PreBötzinger complex: a brainstem region that may generate respiratory rhythm in mammals. Science 254:726-729.

Sturman JA (1993) Taurine in development. Physiol Rev 73:119-147.

Yuste R, Katz LC (1991) Control of postsynaptic $\mathrm{Ca}^{2+}$ influx in developing neocortex by excitatory and inhibitory neurotransmitters. Neuron 6:333-344.

Ziskind-Conhaim L (1998) Physiological functions of GABA-induced depolarizations in the developing rat spinal cord. Perspect Dev Neurobiol 5:279-287. 